(2) Open Access Full Text Article

\title{
Image registration reveals central lens thickness minimally increases during accommodation
}

\author{
This article was published in the following Dove Press journal: \\ Clinical Ophthalmology \\ II September 2017 \\ Number of times this article has been viewed
}

\author{
Ronald A Schachar' \\ Majid Mani² \\ Ira H Schachar ${ }^{3}$ \\ 'Department of Physics, University \\ of Texas at Arlington, Arlington, TX, \\ ${ }^{2}$ California Retina Associates, El \\ Centro, ${ }^{3}$ Byers Eye Institute of \\ Stanford University, Palo Alto, \\ CA, USA
}

Purpose: To evaluate anterior chamber depth, central crystalline lens thickness and lens curvature during accommodation.

Setting: California Retina Associates, El Centro, CA, USA.

Design: Healthy volunteer, prospective, clinical research swept-source optical coherence biometric image registration study of accommodation.

Methods: Ten subjects ( 4 females and 6 males) with an average age of 22.5 years (range: 20-26 years) participated in the study. A $45^{\circ}$ beam splitter attached to a Zeiss IOLMaster 700 (Carl Zeiss Meditec Inc., Jena, Germany) biometer enabled simultaneous imaging of the cornea, anterior chamber, entire central crystalline lens and fovea in the dilated right eyes of subjects before, and during focus on a target $11 \mathrm{~cm}$ from the cornea. Images with superimposable foveal images, obtained before and during accommodation, that met all of the predetermined alignment criteria were selected for comparison. This registration requirement assured that changes in anterior chamber depth and central lens thickness could be accurately and reliably measured. The lens radii of curvatures were measured with a pixel stick circle.

Results: Images from only 3 of 10 subjects met the predetermined criteria for registration. Mean anterior chamber depth decreased, $-67 \mu \mathrm{m}$ (range: -0.40 to $-110 \mu \mathrm{m}$ ), and mean central lens thickness increased, $117 \mu \mathrm{m}$ (range: $100-130 \mu \mathrm{m}$ ). The lens surfaces steepened, anterior greater than posterior, while the lens, itself, did not move or shift its position as appeared from the lack of movement of the lens nucleus, during 7.8 diopters of accommodation, (range: 6.6-9.7 diopters).

Conclusion: Image registration, with stable invariant references for image correspondence, reveals that during accommodation a large increase in lens surface curvatures is associated with only a small increase in central lens thickness and no change in lens position.

Keywords: swept-source biometry, accommodation, anterior chamber depth, crystalline lens thickness, image registration, lens curvature

\section{Background}

Continued disagreement exists as to the fundamental mechanism of accommodation in humans. Despite over 150 years of research, 2 theories remain. The Helmholtz theory hypothesizes that during accommodation, the zonules relax causing the lens to round up with a large increase in central lens thickness ( $>35 \mu \mathrm{m} /$ diopter of accommodation) and anterior movement of the lens. ${ }^{1-3}$ In contrast, the Schachar mechanism ${ }^{4}$ states that during accommodation, the equatorial zonules increase in tension causing peripheral lens flattening and a small increase in central lens thickness $(<20 \mu \mathrm{m} /$ diopter of accommodation) while the lens remains stable. ${ }^{2-4}$ Both theories predict central lens thickness will increase; however, Helmholtz predicts a much larger increase than Schachar. The fundamental difference between the 2 theories is the magnitude of the
Correspondence: Ronald A Schachar Department of Physics, University of Texas at Arlington, PO Box 8669 , La Jolla, CA 92038, USA

$\mathrm{Tel}+\mathrm{I} 858784$ I705

Fax + I 877 48I 093I

Email ron@2ras.com 
change in central lens thickness and the extent and direction of the change in equatorial lens diameter.

Given these differences, it seems that modern imaging of the lens in the unaccommodated and accommodated state could readily distinguish between these 2 theories. However, during accommodation, even with 1 eye patched, the viewing eye cyclotorts ${ }^{5-7}$ and since the eye does not have a fixed point of rotation, the whole eye also shifts. ${ }^{8}$ These extraocular movements are not random and introduce significant alignment errors when comparing accommodated and unaccommodated images. ${ }^{6}$ Moreover, the microsaccades of the eye make identifying corresponding images for perfect registration difficult. The result has been a continued disagreement for interpreting lens measurements acquired at baseline and during accommodation.

In order to differentiate between these 2 mechanisms of accommodation, high resolution and proper image registration are a prerequisite. To satisfy these basic criteria, the most advanced commercially available ocular swept-source optical coherent tomographic biometer, the Zeiss IOLMaster 700 (Carl Zeiss Meditec Inc., Jena, Germany) was used. The swept source optical coherence biometer has the advantage of long range and higher sampling rates than can typically be obtained with spectral/Fourier domain optical coherence tomography. ${ }^{9,10}$ The Zeiss IOLMaster 700 simultaneously images the cornea, anterior chamber, entire central crystalline lens and fovea, with a standard deviation of repeat measurements in the optic axis of $10 \mu \mathrm{m}$ for the anterior chamber depth and $20 \mu \mathrm{m}$ for the lens thickness. ${ }^{11,12}$ In addition to measuring central corneal thickness and axial length, the instrument has a video camera and keratometer to measure the center of the cornea relative to the visual axis, white-towhite (WTW; corneoscleral margins), corneal curvature, corneal astigmatic axis and pupil diameter.

A distinct advantage of the Zeiss IOLMaster 700 is that it captures high resolution sagittal sections of both the shape of the cornea and fovea allowing for 2 non-changing positional references separated by over $20 \mathrm{~mm}$ for image comparison. ${ }^{4,6,13,14}$ Using pre-established criteria for alignment, registrable image pairs can be used to reliably compare changes in intraocular structures between the baseline and accommodated state.

To minimize the effects of motion artifact, image registration is standard practice. It significantly improves measurement accuracy and detection of conformational changes. ${ }^{15-19}$ The advantages of image registration have become apparent in ophthalmology when it was incorporated into commercially available optical coherent tomographic instruments designed for examining the posterior segment of the eye. Measurements of change in retinal nerve fiber layer and central retinal thickness have become more accurate..$^{20-21}$ Detection of subtle retinal pathologies, not visible in the past, is now routinely observed..$^{22-24}$ Unfortunately, there is no commercially available instrument that incorporates image registration for assessing the anterior segment of the eye. Consequently, reported accommodative lens directional and dimensional changes may be exaggerated and/or distorted. This is the first study to incorporate invariant stable positional references separated by $>20 \mathrm{~mm}$ to measure the changes in central lens thickness during accommodation. A recent study of accommodative lens changes used the location of the pupil and the shape of the iris to determine image correspondence for image registration. ${ }^{25}$ Since both the location of the pupil and shape of the iris change with accommodation, even during phenylephrine dilation, ${ }^{26-32}$ reliance on these unstable references ensured that compared images were not properly registered.

\section{Methods}

\section{Subjects}

Ten subjects (4 females and 6 males) with an average age of 22.5 years (range: $20-26$ years) participated in this prospective cohort study. They were healthy ophthalmic technicians from the staff of California Retina Associates. All subjects agreed to participate and executed an informed consent. This study complied with the tenets of the Declaration of Helsinki and was approved by the Ethics Committee of the California Retina Associates.

All subjects had normal ocular examinations. Each had best corrected visual acuity of 20/20 and a mean spherical equivalent refraction of -1.01 diopters (range: 0.125 to -4.50 diopters). None were using any medications, supplements nor any recreational drugs that would affect accommodation.

\section{Measurement system}

The Zeiss IOLMaster 700 (Carl Zeiss Meditec Inc.) was used for image acquisition. The ring (Zeiss part number 0239-805) that retains the cover of the IOLMaster 700 was replaced with a ring modified to hold a 3.147" diameter semicircle $1.1 \mathrm{~mm}$ thick beam splitter (Newport Corp., Franklin, MA, USA) at $45^{\circ}$ with respect to the optical axis of the biometer. The transmission of the beam splitter at $45^{\circ}$ was $\geq 95 \%$ for wavelengths from 500 to $1,100 \mathrm{~nm}$ and $99.5 \%$ reflective at $415 \mathrm{~nm}$. Using an $x-y-z$ mechanical stage affixed to the top of the biometer, a $415 \mathrm{~nm}$ light emitting diode flashlight (Zhishunjia Industry Co., Shenzhen, China) was supported at 

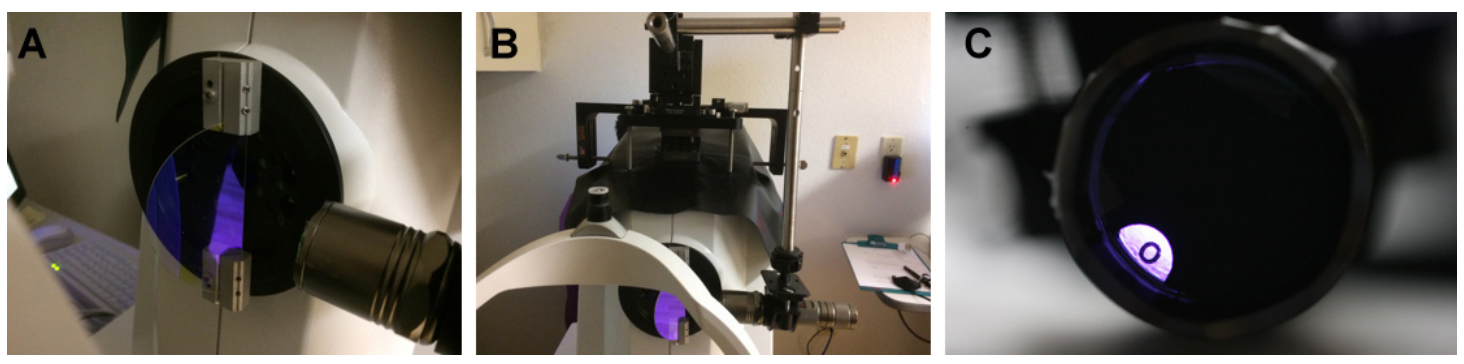

Figure I Photographs of the modified IOLMaster 700 swept-source.

Notes: (A) The beam splitter mounted on the cover retaining ring. (B) The mechanical stage mounted at the top of the biometer to control the position of the 4 I $5 \mathrm{~nm}$ LED flashlight. (C) A photograph showing the fixation 20/50 near letter "O" target illuminated by the flashlight with the rest of the flashlight lens covered.

the side of the instrument (Figure 1). A 20/50 near chart black letter "O" on a transparent film was attached to the flashlight lens. A black piece of paper with a peripheral hole was used to cover the glass of the flashlight, except at the location of the letter (Figure 1C). The luminance of the target was $\sim 100 \mathrm{~cd} / \mathrm{m}^{2}$, similar to a near chart, ${ }^{33}$ as measured with a luminance meter (Model LS-110, Minolta Camera Co, Ltd., Osaka, Japan). With the beam splitter in place, the biometer was calibrated using the method described by the manufacturer. ${ }^{11}$

\section{Measurement procedure}

Forty-five minutes after placing 1 drop of phenylephrine $10 \%$ in the right eye (1gtt every $1 \mathrm{~min} \times 3)$, which did not affect accommodative amplitude, ${ }^{34} 3$ unaccommodated biometric measurements were performed. For the measurements, the subjects fixated on the internal target light of the IOLMaster 700 with their uncorrected right eyes while their left eyes were patched. Then the flashlight was turned on and positioned, using the mechanical stage, until the subject confirmed the 20/50 letter was in focus and the fixation light of the biometer was aligned in the center of the letter. To stimulate maximum accommodation, a target distance of $11 \mathrm{~cm}$ from the eye was chosen to induce 9.0 diopters of accommodation, which was within 3 standard deviations of the reported objectively measured mean accommodative amplitude for this age group. ${ }^{35,36}$ While the subject maintained focus and alignment with the target letter at $11 \mathrm{~cm}$ from the cornea, 3 consecutive, accommodated biometric measurements were obtained. During all measurements, the light in the room was kept at the same overall illumination.

\section{Image analysis}

Using the predetermined positional references, which do not change position during accommodation, image alignment of multiple images was performed in order to find an acceptable pair for comparison. The stable references used in this study were corneal thickness, corneal optical power (spherical equivalent keratometry), corneal astigmatic axis, corneal diameter (WTW), center of the cornea and axial length. .,13,14,37,38 $^{2}$

The pupil size had to be $>4.0 \mathrm{~mm}$ and the displacements between the stable positional references for the image pairs, selected for final comparison, were required to meet the following criteria:

1. Corneal thickness $\leq 5 \mu \mathrm{m}$

2. Spherical equivalent keratometry $\leq 0.15$ diopters

3. Corneal astigmatic axis $\leq 4^{\circ}$

4. $\mathrm{WTW} \leq 100 \mu \mathrm{m}$

5. Center of the cornea related to the visual axis $\leq 150 \mu \mathrm{m}$ (calculated from the $\mathrm{x}$ and $\mathrm{y}$ coordinates specified by the biometer)

6. Axial length $\leq 15 \mu \mathrm{m}$.

The threshold criterion for each stable parameter above was based on the reported standard deviation of the repeatability for that parameter measured by the IOLMaster 700. ${ }^{11}$ Consistent with the generally acceptable difference between clinical measurements, ${ }^{39}$ a difference less than or equal to twice the reported standard deviation for the repeatability was chosen as the threshold for acceptable pairing of images. Additionally, a 400\% magnification of the foveal images of the paired accommodated and unaccommodated images had to be registrable.

Once a pair was established, based on the above criteria, each digitized image was again magnified to $400 \%$. The images were scaled using pixel software (Pixel Stick 2.9 for the Mac; Plum Amazing LLC, Princeville, HI, USA) and the central lens thickness specified by the biometer. Then the circle of the pixel stick was sized until it was superimposable on the anterior lens surface and then sized until it was superimposable on the posterior lens surface to determine their radii of curvatures. To validate this method of curvature measurement, the circle of the pixel stick was sized until it 
was superimposable on the anterior corneal surface and the calculated corneal radius of curvature was compared with the vertical keratometry specified by the biometer. The measurements were made manually and the examiner was masked. Repeatability was not assessed; however, the IOLMaster 700 reports are included in Figure 2 for anyone to repeat.

Central optical power (COP) of the lens was calculated with the following formula: ${ }^{4}$

$$
\operatorname{COP}=\frac{n_{1}-n_{a}}{r_{a}}-\frac{n_{1}-n_{a}}{r_{p}}+\frac{t\left(n_{1}-n_{a}\right)^{2}}{r_{a} r_{p} n_{1}}
$$

where $\mathrm{n}_{1}$ is the refractive index of the lens, $1.42, \mathrm{n}_{\mathrm{a}}$ is the refractive index of the aqueous and vitreous, 1.336, $\mathrm{t}$ is the central lens thickness and $r_{a}$ and $r_{p}$ are the the radii of curvatures of the anterior and posterior curvatures, respectively. Following the standard convention for a concave surface, the posterior lens radius of curvature was designated minus.

\section{Results}

\section{Subjects with registrable images}

Of the 10 study subjects with 30 baseline and 30 accommodated images, only 1 baseline and 1 accommodated image from just 3 subjects met the stringent registration criteria for analysis. For these 3 subjects, the maximum difference between the baseline and accommodative images for: the location of the corneal center was $141 \mu \mathrm{m}$, central corneal thickness was $5 \mu \mathrm{m}$, spherical equivalent keratometry was 0.13 diopters, astigmatic axis was $4^{\circ}$, WTW (corneal diameter) was $100 \mu \mathrm{m}$ and axial length was $10 \mu \mathrm{m}$ (Figure 2). In addition, their foveas were registrable. Age, spherical equivalent refraction and differences between the stable parameters for the paired accommodated and unaccommodated images ( 1 image from each accommodative state) from each of the 3 subjects are given in Table 1 .

Forty-five minutes after administration of phenylephrine, the pupil sizes of subjects 1, 2 and 3 were 7.6, 8.6 and $8.3 \mathrm{~mm}$. Their pupils constricted 3.1, 1.8 and $2.1 \mathrm{~mm}$ (mean of $2.3 \mathrm{~mm}$ ) to $4.5,6.8$ and $6.2 \mathrm{~mm}$ while focusing on the near target (Figure 2). Superimposition and registration of the foveal images from the image pairs is shown in Figure 3.

\section{Measurement of anterior and posterior lens radii of curvatures}

Matching of the pixel stick circles along with the radius of curvatures of the unaccommodated and accommodated anterior corneal surface and anterior and posterior lens surfaces are shown in Figures 4 and 5.
The anterior corneal surface and each lens surface radius of curvature were converted to millimeters using the following:

$\operatorname{RoC}(\mathrm{mm})=\frac{\text { Central lens thickness }(\mathrm{mm})}{\text { Central lens thickness }(\text { pixels })} \times \operatorname{RoC}($ pixels $)$

where, $\mathrm{RoC}=$ surface radius of curvature. For the conversion from millimeters to pixels, the central lens thickness of each subject and each accommodative state was used to individualize scaling of the pixel circle measurement for each image. Comparisons of the calculated anterior corneal radius of curvature to the biometer specified vertical keratometry and the calculated lens surface radii of curvatures are given in Tables 2 and 3, respectively.

The standard deviation of the mean difference between the calculated and biometer-measured vertical keratometry was $\pm 140 \mu \mathrm{m}$, implying that the biometric images were not distorted and the precision (2 standard deviations) for the pixel circle lens radius measurements was approximately $\pm 300 \mu \mathrm{m}$.

\section{Change in anterior chamber depth and central lens thickness}

The change associated with accommodation in anterior chamber depth, central lens thickness, anterior and posterior radii of curvatures and COP are given in Table 4 .

The mean decrease in anterior chamber depth, increase in central lens thickness and decrease in vitreous length was $-67,117$ and $-40 \mu \mathrm{m}$, respectively. Based on the measured radius of curvature of each lens surface, the average calculated increase in central lens optical power was 7.78 diopters. This compares closely with the accommodation stimulated by a near target at $11 \mathrm{~cm}$ from the cornea in these eyes without any correction. The difference between the calculated change in lens optical power and the expected accommodation (accommodative stimulus minus the spherical equivalent of the refraction) was +0.69 diopters (9.69-9.00 diopters), -1.36 diopters (7.01-8.365) and -0.36 diopters (6.64-7.0 diopters). The mean difference was -0.34 diopters.

\section{Registration of the cornea and fovea}

Superimposition of the corneas and foveas of the entire sagittal sections of the accommodated on top of the unaccommodated eyes of the subjects revealed the lens was stable and did not move anteriorly, posteriorly or downward during accommodation as appeared from the lack of movement of the lens nucleus (Figure 6). 
A

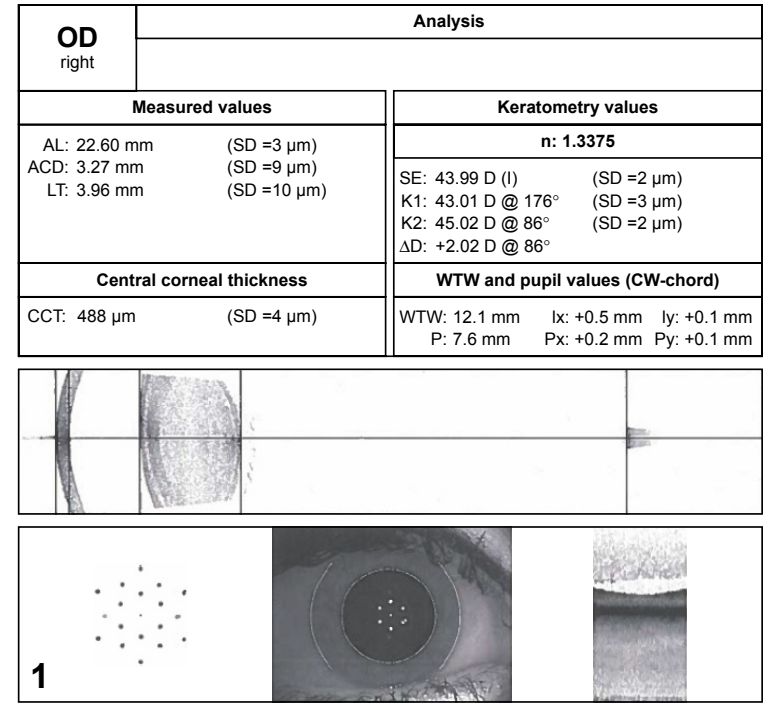

\begin{tabular}{|c|c|c|c|}
\hline$\underset{\text { right }}{\text { OD }}$ & & \multicolumn{2}{|l|}{ Analysis } \\
\hline \multicolumn{2}{|c|}{ Measured values } & \multicolumn{2}{|c|}{ Keratometry values } \\
\hline \multirow{2}{*}{$\begin{array}{r}\text { AL: } 23.92 \mathrm{~mm} \\
\text { ACD: } 3.89 \mathrm{~mm} \\
\text { LT: } 3.31 \mathrm{~mm}\end{array}$} & \multirow{2}{*}{$\begin{array}{l}(\mathrm{SD}=6 \mu \mathrm{m}) \\
(\mathrm{SD}=8 \mu \mathrm{m}) \\
(\mathrm{SD}=10 \mu \mathrm{m})\end{array}$} & \multicolumn{2}{|r|}{$\mathrm{n}: \mathbf{1 . 3 3 7 5}$} \\
\hline & & $\begin{array}{l}\text { SE: } 44.07 \mathrm{D} \\
\text { K1: } 43.75 \mathrm{D} @ 9^{\circ} \\
\text { K2: } 44.40 \mathrm{D} @ 99^{\circ} \\
\Delta \mathrm{D}:+0.65 \mathrm{D} @ 99^{\circ}\end{array}$ & $\begin{array}{l}(\mathrm{SD}=3 \mu \mathrm{m}) \\
(\mathrm{SD}=3 \mu \mathrm{m}) \\
(\mathrm{SD}=7 \mu \mathrm{m})\end{array}$ \\
\hline \multicolumn{2}{|c|}{ Central corneal thickness } & \multicolumn{2}{|c|}{ WTW and pupil values (CW-chord) } \\
\hline ССТ: $590 \mu \mathrm{m}$ & $(\mathrm{SD}=4 \mu \mathrm{m})$ & $\begin{array}{l}\text { WTW: } 12.2 \mathrm{~mm} \\
\text { P: } 8.6 \mathrm{~mm}\end{array}$ & $\begin{array}{rr}\text { Ix: }+0.4 \mathrm{~mm} & \text { ly: }+0.1 \mathrm{~mm} \\
\text { Px: }+0.2 \mathrm{~mm} & \text { Py: }+0.1 \mathrm{~mm}\end{array}$ \\
\hline
\end{tabular}
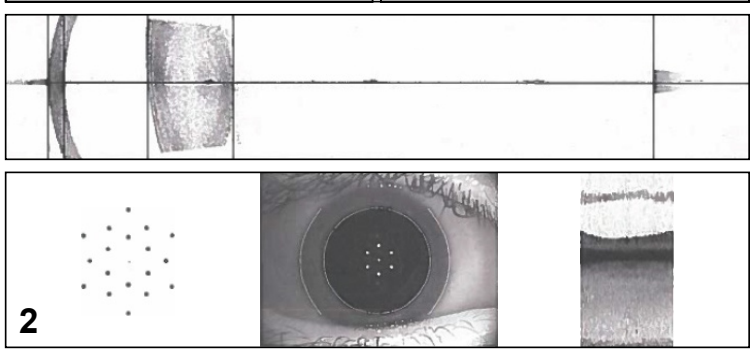

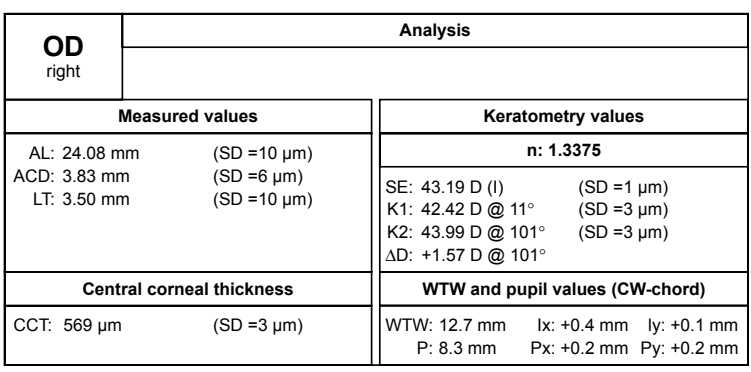
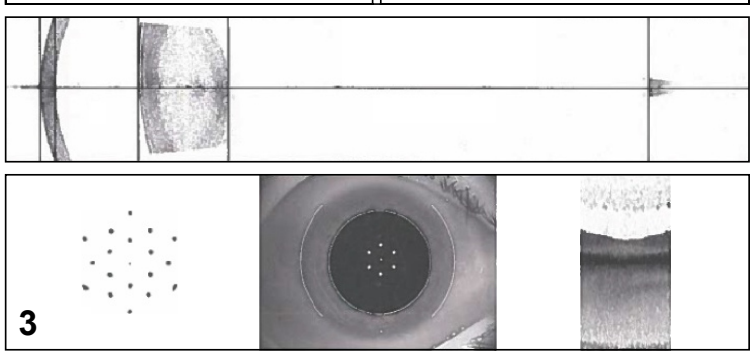

B

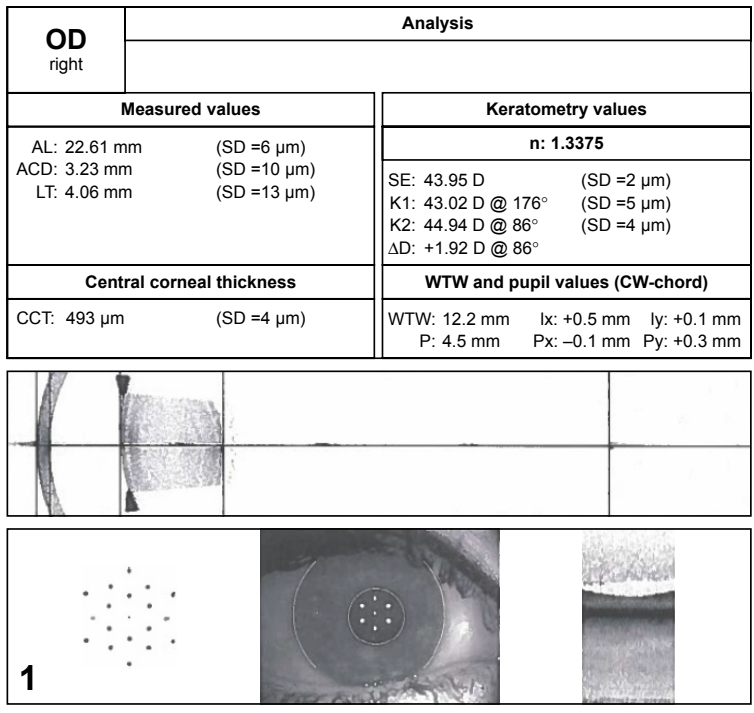

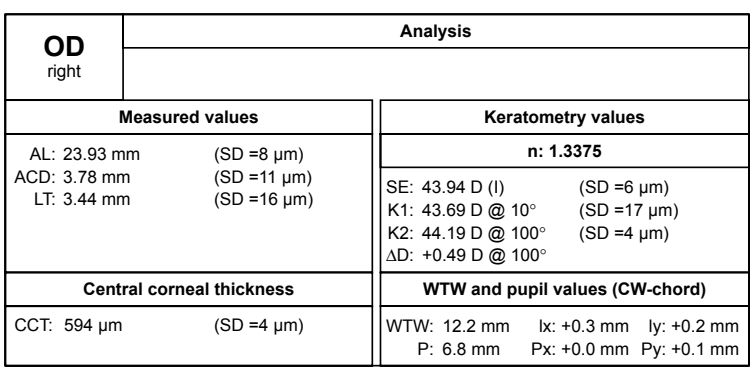
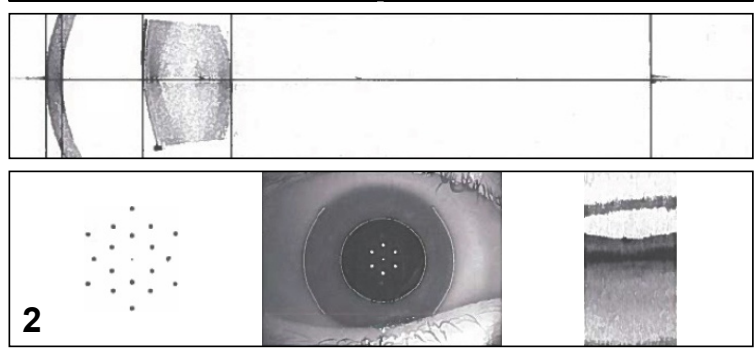

\begin{tabular}{|c|c|c|c|}
\hline$\underset{\text { right }}{\text { OD }}$ & & \multicolumn{2}{|l|}{ Analysis } \\
\hline \multicolumn{2}{|c|}{ Measured values } & \multicolumn{2}{|c|}{ Keratometry values } \\
\hline \multirow{2}{*}{$\begin{array}{r}\text { AL: } 24.09 \mathrm{~mm} \\
\text { ACD: } 3.78 \mathrm{~mm} \\
\text { LT: } 3.62 \mathrm{~mm}\end{array}$} & \multirow{2}{*}{$\begin{array}{l}(\mathrm{SD}=5 \mu \mathrm{m}) \\
(\mathrm{SD}=8 \mu \mathrm{m}) \\
(\mathrm{SD}=16 \mu \mathrm{m})\end{array}$} & \multicolumn{2}{|c|}{$\mathrm{n}: 1.3375$} \\
\hline & & $\begin{array}{l}\text { SE: 43.11D (I) } \\
\text { K1: 42.01D } @ 7^{\circ} \\
\text { K2: 44.26D } @ 97^{\circ} \\
\Delta \mathrm{D}:+2.25 \mathrm{D} @ 97^{\circ}\end{array}$ & $\begin{array}{l}(\mathrm{SD}=2 \mu \mathrm{m}) \\
(\mathrm{SD}=6 \mu \mathrm{m}) \\
(\mathrm{SD}=3 \mu \mathrm{m})\end{array}$ \\
\hline \multicolumn{2}{|c|}{ Central corneal thickness } & \multicolumn{2}{|c|}{ WTW and pupil values (CW-chord) } \\
\hline ССТ: $570 \mu \mathrm{m}$ & $(\mathrm{SD}=3 \mu \mathrm{m})$ & $\begin{array}{l}\text { WTW: } 12.6 \mathrm{~mm} \\
\text { P: } 6.2 \mathrm{~mm}\end{array}$ & $\begin{array}{l}+0.3 \mathrm{~mm} \text { ly: }+0.1 \mathrm{~mm} \\
+0.0 \mathrm{~mm} \text { Py: }+0.5 \mathrm{~mm}\end{array}$ \\
\hline
\end{tabular}
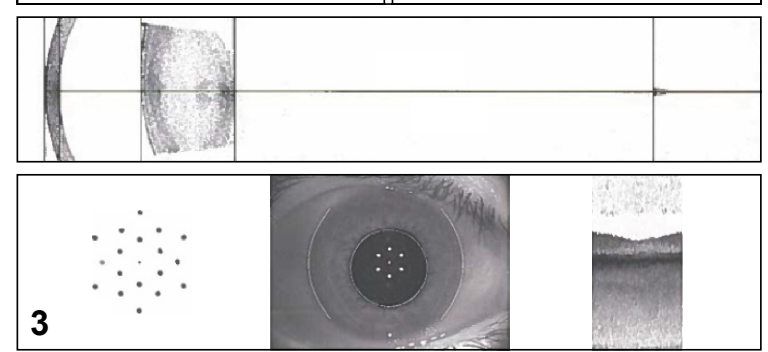

Figure 2 Data output from the IOL master for subjects I, 2 and 3.

Notes: (A) Unaccommodated. (B) Accommodated. Note that the subjects' pupils constricted and their lenses increased in thickness while focusing on the near target. Abbreviations: ACD, anterior chamber depth; AL, axial length; LT, lens thickness; SE, spherical equivalent; WTW, white-to-white. 
Table I Subject age, baseline spherical equivalent refraction and differences between accommodated and unaccommodated preselected parameters

\begin{tabular}{|c|c|c|c|c|c|c|c|c|}
\hline \multirow[t]{2}{*}{ Subject } & \multirow{2}{*}{$\begin{array}{l}\text { Age } \\
\text { (years) }\end{array}$} & \multirow{2}{*}{$\begin{array}{l}\text { Baseline SER } \\
\text { (diopters) }\end{array}$} & \multicolumn{6}{|c|}{ Accommodated - unaccommodated } \\
\hline & & & CCT $(\mu \mathrm{m})$ & $\begin{array}{l}\text { SEK } \\
\text { (diopters) }\end{array}$ & $\begin{array}{l}\text { Astigmatic } \\
\text { axis }\left({ }^{\circ}\right)\end{array}$ & WTW $(\mu \mathrm{m})$ & $\begin{array}{l}\text { Corneal } \\
\text { center }(\mu \mathrm{m})\end{array}$ & $\begin{array}{l}\text { Axial } \\
\text { length }(\mu \mathrm{m})\end{array}$ \\
\hline I & 24 & 0.00 & 5 & -0.05 & 0 & 100 & 0 & 10 \\
\hline 2 & 21 & -0.635 & 4 & -0.13 & $\mathrm{I}$ & 0 & $|4|$ & 10 \\
\hline 3 & 20 & -2.00 & 1 & -0.08 & -4 & -100 & 100 & 10 \\
\hline Average & 21.7 & -1.04 & 3 & -0.08 & -1 & 0 & 80.3 & 10 \\
\hline SD & 2.1 & 0.88 & 2 & 0 & 2.6 & 100 & 72.5 & 0 \\
\hline
\end{tabular}

Abbreviations: CCT, central corneal thickness; SEK, spherical equivalent keratometry; SER, spherical equivalent refraction; WTW, white-to-white.

\section{Discussion}

Accommodation induces cyclotorsion and convergence of the eye. These non-random changes in ocular alignment can systematically bias lens measurements if not carefully guarded against using precise image registration techniques. Accordingly, we set stringent inclusion criteria to find matching image pairs to guarantee appropriate comparison between intraocular structures.

Using a carefully designed target and the most advanced swept-source coherence tomographic biometer (Zeiss IOLMaster 700), we attempted to match baseline and accommodated images. To our surprise, even using this biometer, only 3 of 10 subjects satisfied the stringent inclusion criteria needed to identify perfectly registrable images from the accommodated and unaccommodated state. The difficulty in finding perfectly registrable matching images is likely a consequence of both the changes in ocular alignment and the microsaccadic movements that occur continuously in the fixating eye. Despite these challenges, 3 subjects were successfully identified who met the stringent inclusion criteria.

Another pitfall in researching lens changes during accommodation is that, in the absence of pharmacologic activation, accommodation is an effort-dependent process. Therefore, care must be taken to assure subjects are in fact accommodating. This point is especially important when assessing Schachar's mechanism as it contends small increases in lens thickness and no change in lens position. Two important features were used to confirm accommodative amplitude.
A

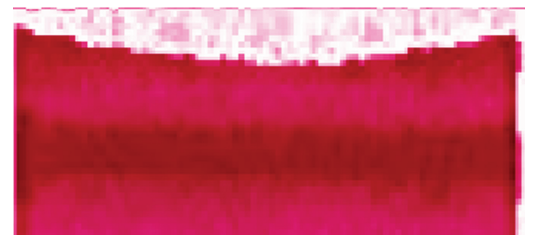

2

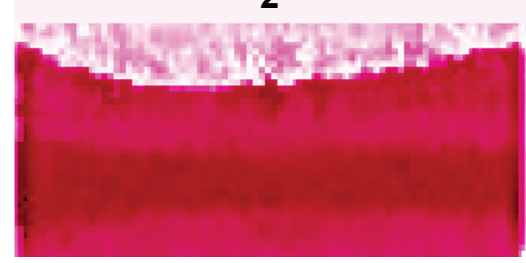

3

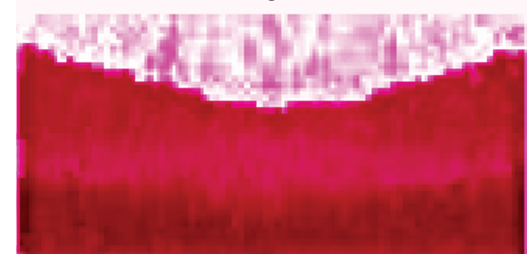

B

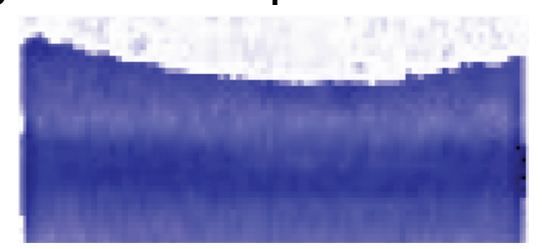

2

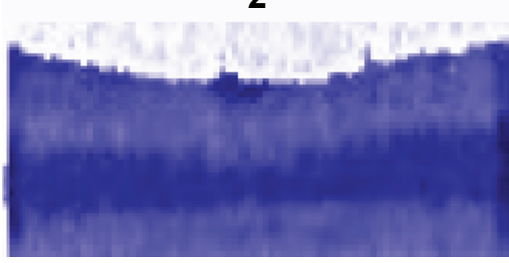

3

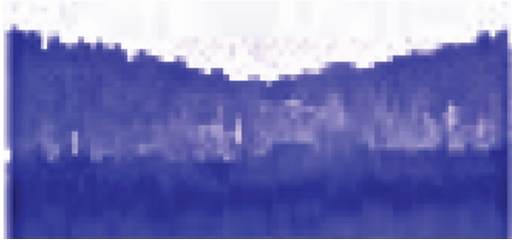

C

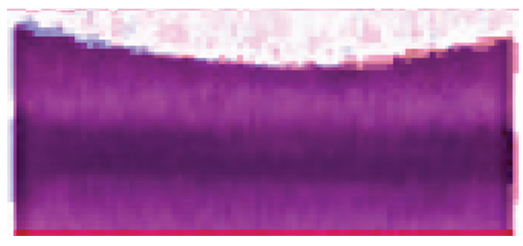

2

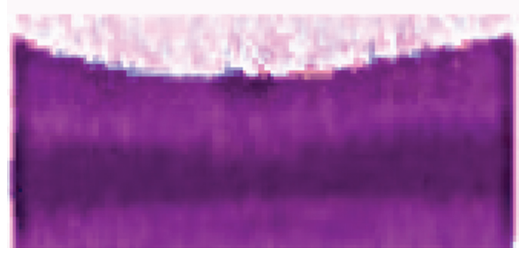

3

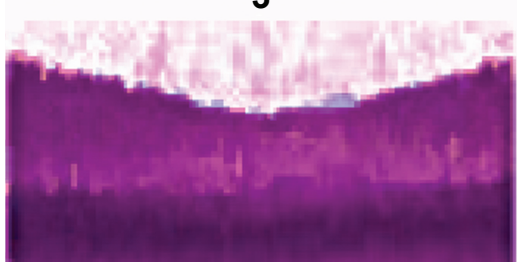

Figure 3 IOLMaster 700 foveal images of subjects I, 2 and 3.

Notes: (A) Unaccommodated (red). (B) Accommodated (blue). (C) Accommodated superimposed on unaccommodated showing registration. 

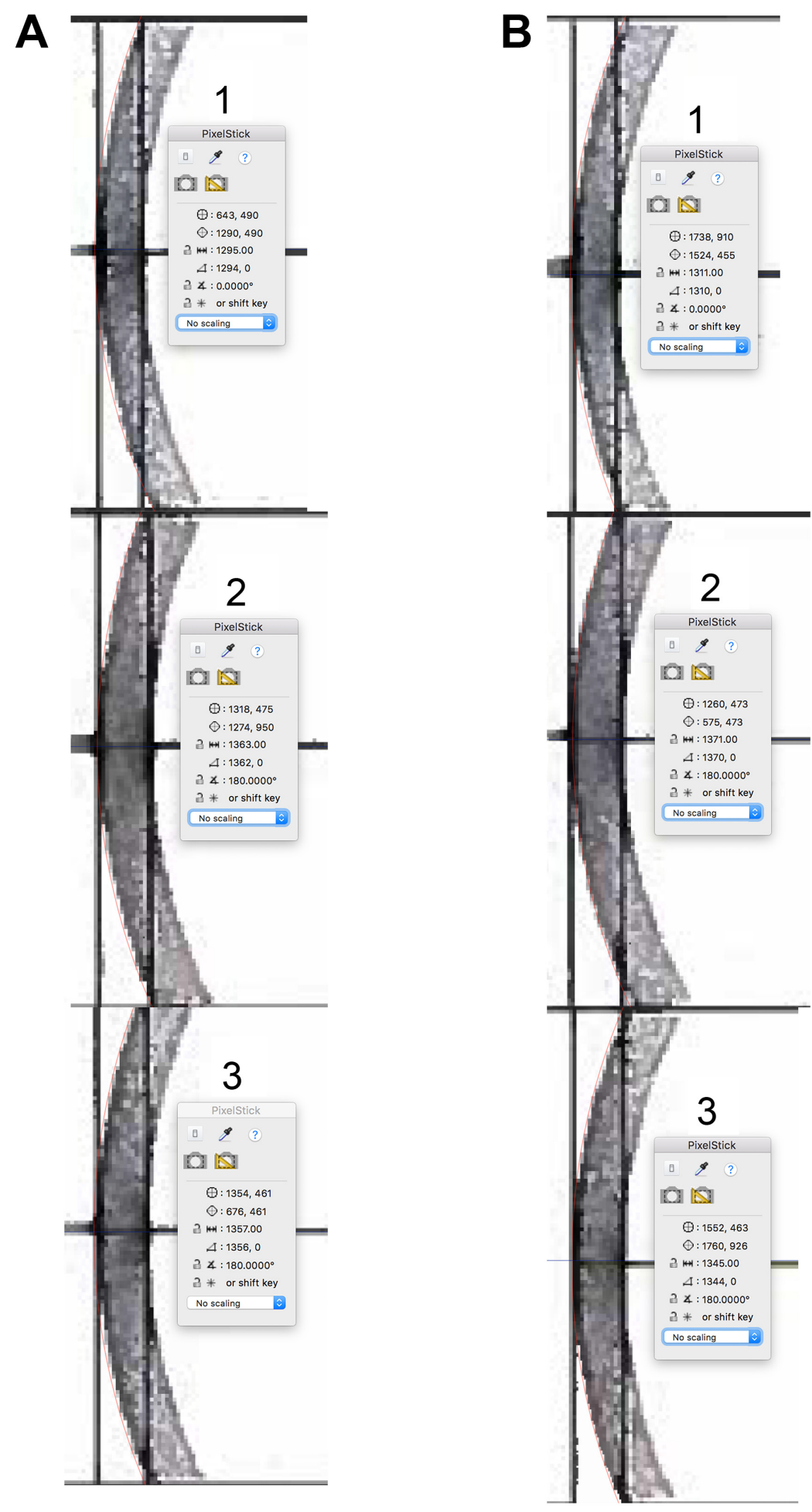

Figure 4 IOLMaster 700 corneal images of subjects I, 2 and 3 showing the radius of curvature in pixels for the circle that matched the anterior vertical surface of the cornea.

Notes: (A) Unaccommodated. (B) Accommodated anterior corneal surface. The fine red line of the pixel stick circle is only easily seen when the image is magnified to make the central corneal thickness $\sim 0.5^{\prime \prime}$.

First, pupil constriction occurred in all subjects in the accommodative state despite having received a strong adrenergic agonist. Second, central lens thickness increased when the subjects were focusing at near. Third, by measur- ing the change in lens curvatures during accommodation, we were able to confirm average accommodative amplitude of 7.8 diopters. Because subjects were imaged without their refraction, we compared the calculated change in lens 

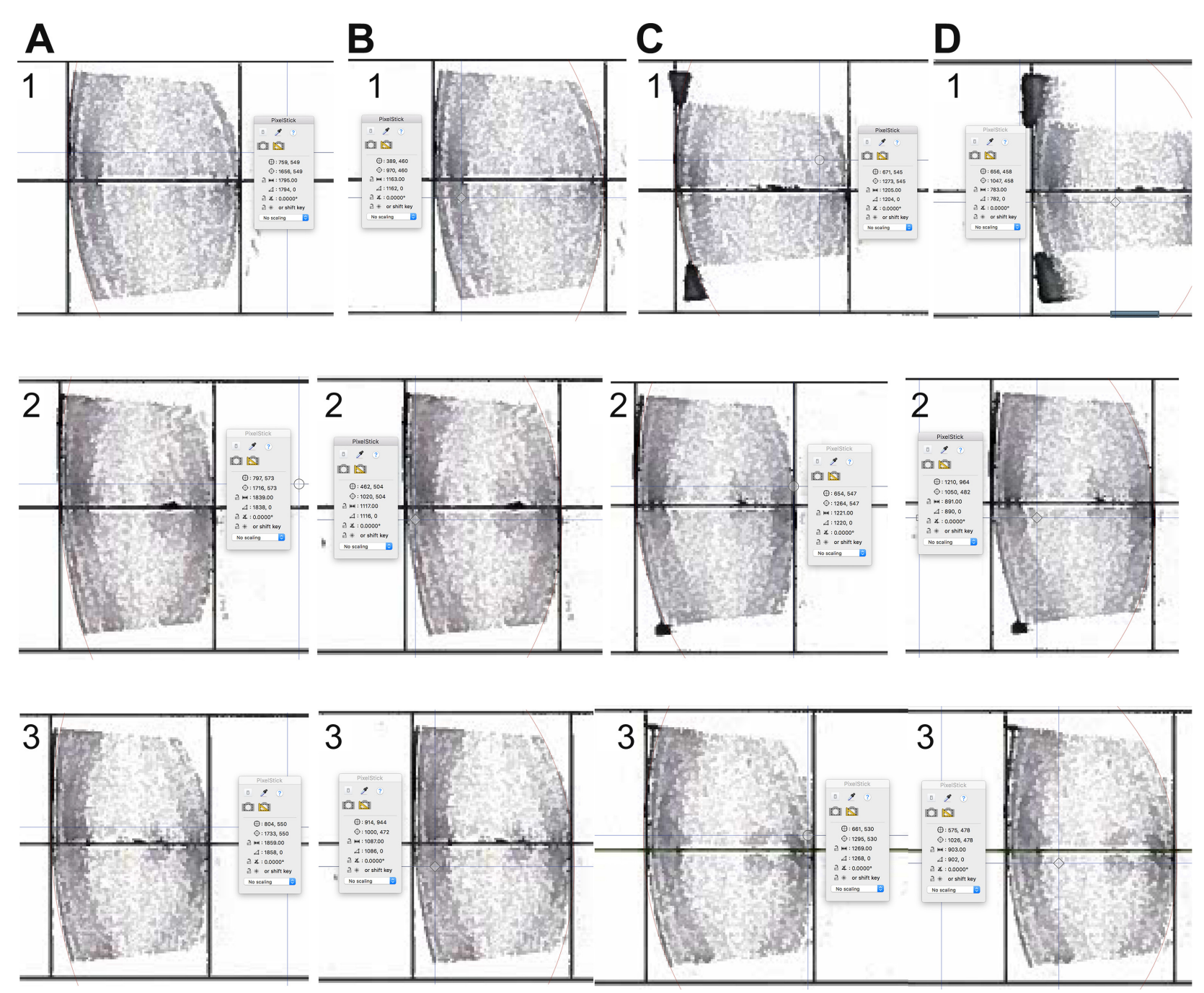

Figure 5 IOLMaster 700 lens images of subjects I, 2 and 3 showing the radius of curvature in pixels for the circle that matched the unaccommodated and accommodated lens surfaces.

Notes: Unaccommodated (A) anterior and (B) posterior. Accommodated (C) anterior and (D) posterior lens surfaces. The fine red line of the pixel stick circle is only easily seen when the image is magnified to make the central thickness $\sim 3^{\prime \prime}$.

power with the predicted amount of accommodative amplitude needed to resolve the near target given their baseline refractions and found a mean difference of $<0.50$ diopters, further confirming that the subjects were accommodating on the near target.
The calculated accommodative amplitude for subject 1 was 9.67 diopters, which was less than one tenth of a diopter above 3 standard deviations of the reported objectively measured mean accommodative amplitude, 6.25 diopters \pm 1.13 diopters for subjects in this age group. ${ }^{35,36}$ Although not

Table 2 Comparison of measured anterior corneal radius to IOLMaster 700 vertical keratometry

\begin{tabular}{|c|c|c|c|c|c|c|c|c|c|c|}
\hline \multirow[t]{2}{*}{ Subject } & \multicolumn{5}{|c|}{ Unaccommodated } & \multicolumn{5}{|c|}{ Accommodated } \\
\hline & $\begin{array}{l}\text { CR } \\
\text { (pixels) }\end{array}$ & $\begin{array}{l}\text { CR } \\
(\mathrm{mm})\end{array}$ & $\begin{array}{l}\text { VK } \\
\text { (diopters) }\end{array}$ & $\begin{array}{l}\text { VK } \\
(\mathrm{mm})\end{array}$ & $\begin{array}{l}\text { CR - VK } \\
(\mu \mathrm{m})\end{array}$ & $\begin{array}{l}\text { CR } \\
\text { (pixels) }\end{array}$ & $\begin{array}{l}\text { CR } \\
(\mathrm{mm})\end{array}$ & $\begin{array}{l}\text { VK } \\
\text { (diopters) }\end{array}$ & $\begin{array}{l}\text { VK } \\
(\mathrm{mm})\end{array}$ & $\begin{array}{l}\text { CR - VK } \\
(\mu \mathrm{m})\end{array}$ \\
\hline I & 1,295 & 7.38 & 45.02 & 7.46 & -83 & $|, 3| \mid$ & 7.42 & 44.94 & 7.48 & -57 \\
\hline 2 & 1,363 & 7.68 & 44.40 & 7.57 & 112 & I,37| & 7.70 & 44.19 & 7.60 & 96 \\
\hline 3 & $\mathrm{I}, 357$ & 7.65 & 43.99 & 7.64 & 12 & $\mathrm{I}, 345$ & 7.50 & 44.26 & 7.59 & -92 \\
\hline Average & $\mathrm{I}, 338$ & 7.57 & 44.47 & 7.56 & 14 & $\mathrm{I}, 342$ & 7.54 & 44.46 & 7.56 & -17 \\
\hline SD & 38 & 0.16 & 0.52 & 0.09 & 98 & 30 & 0.14 & $0.4 I$ & 0.07 & 100 \\
\hline
\end{tabular}

Abbreviations: $\mathrm{CR}$, measured corneal anterior radius; VK, vertical keratometry. 
Table 3 Conversion of lens surface curvatures from pixels to millimeters

\begin{tabular}{|c|c|c|c|c|c|c|c|c|c|c|c|c|}
\hline \multirow[t]{2}{*}{ Subject } & \multicolumn{6}{|c|}{ Unaccommodated } & \multicolumn{6}{|c|}{ Accommodated } \\
\hline & $\begin{array}{l}\text { CLT } \\
\text { (pixels) }\end{array}$ & $\begin{array}{l}\text { CLT } \\
(\mathrm{mm})\end{array}$ & $\begin{array}{l}\text { AR } \\
\text { (pixels) }\end{array}$ & $\begin{array}{l}\text { AR } \\
(\mathrm{mm})\end{array}$ & $\begin{array}{l}\text { PR } \\
\text { (pixels) }\end{array}$ & $\begin{array}{l}\text { PR } \\
(\mathrm{mm})\end{array}$ & $\begin{array}{l}\text { CLT } \\
\text { (pixels) }\end{array}$ & $\begin{array}{l}\text { CLT } \\
(\mathrm{mm})\end{array}$ & $\begin{array}{l}\text { AR } \\
\text { (pixels) }\end{array}$ & $\begin{array}{l}\text { AR } \\
(\mathrm{mm})\end{array}$ & $\begin{array}{l}\text { PR } \\
\text { (pixels) }\end{array}$ & $\begin{array}{l}\text { PR } \\
(\mathrm{mm})\end{array}$ \\
\hline I & 695 & 3.96 & $\mathrm{I}, 795$ & 10.2 & $\mathrm{I}, 163$ & -6.6 & 717 & 4.06 & $\mathrm{I}, 205$ & 6.8 & 783 & -4.4 \\
\hline 2 & 587 & 3.31 & 1,839 & 10.4 & 1,117 & -6.3 & 607 & 3.44 & $|, 22|$ & 6.9 & 891 & -5.0 \\
\hline 3 & 621 & 3.50 & 1,859 & 10.5 & $\mathrm{I}, 087$ & -6.1 & 649 & 3.62 & 1,269 & 7.1 & 903 & -5.0 \\
\hline Average & 634 & 3.59 & $|, 83|$ & 10.4 & 1,122 & -6.4 & 658 & 3.71 & 1,232 & 6.9 & 859 & -4.8 \\
\hline SD & 55 & 0.33 & 33 & 0.13 & 38 & 0.25 & 56 & 0.32 & 33 & 0.1 & 66 & 0.4 \\
\hline
\end{tabular}

Abbreviations: AR, anterior lens radius; $C L T$, central lens thickness; PR, posterior lens radius.

common, subjects can have an objectively measured accommodative lead; ${ }^{40,41}$ however, even if the accommodative amplitude was actually lower for this subject, it would not meaningfully alter the results.

Having verified that accommodation was occurring and identifying registrable matching image pairs based on the predetermined criteria, the changes in lens thickness and lens position that occur during accommodation could be reliably assessed. For the 3 subjects that met the inclusion criteria, registered images demonstrated that mean anterior chamber depth decreased to $-67 \mu \mathrm{m}$ (range: -40 to $-110 \mu \mathrm{m}$ ), central lens thickness increased to $117 \mu \mathrm{m}$ (range: $100-130 \mu \mathrm{m}$ ), vitreous length decreased to $-40 \mu \mathrm{m}$ (range: $10-60 \mu \mathrm{m}$ ) and anterior and posterior radii of curvatures steepened to $3.4 \mathrm{~mm}$ (range: $3.4-3.5 \mathrm{~mm}$ ) and $1.5 \mathrm{~mm}$ (range: $1.1-2.1 \mathrm{~mm}$ ), during a mean 7.8 diopters of accommodation. On average, anterior chamber depth decreased by $-8.5 \mu \mathrm{m} /$ diopter, central lens thickness increased by $16 \mu \mathrm{m} /$ diopter, and anterior and posterior radii of curvature steepened by $437 \mu \mathrm{m} /$ diopter and $193 \mu \mathrm{m} /$ diopter.

In all 3 subjects, the lens was stable, as evidenced by the lack of apparent movement of the nucleus during accommodation (Figure 6). Since the whole lens did not move and the decrease in anterior chamber depth was greater than the decrease in vitreous length (Table 4), the anterior portion of the lens moved anteriorly more than the posterior portion of the lens moved posteriorly. The larger movement of the anterior portion of the lens was consistent with the greater steepening of the anterior lens surface than the posterior surface.

These findings of small changes in lens thickness associated with large central lens surface steepening and an unchanging lens position are predicted by Schachar's mechanism of accommodation. ${ }^{4}$

\section{Conclusion}

This study highlights that the small changes in anterior chamber depth and central lens thickness during accommodation can easily be masked by extraocular movements, which are large in magnitude. Prior studies have reported exaggerated changes in anterior chamber depth and lens thickness of three or more times greater than in the present study. ${ }^{42-49}$ These prior studies did not use image registration to differentiate the effects of ocular alignment and/or microsaccadic movements. It is well documented that when studies do not incorporate proper image registration, measurements can be inaccurate and/or exaggerated. ${ }^{50-54}$

Although phenylephrine does not appear to have an effect on accommodative amplitude, ${ }^{34}$ pupillary dilation does affect near vision. Therefore, it would be ideal to have a technique that does not require pupillary dilation and has the same or

Table 4 Accommodative changes in anterior chamber depth, lens thickness, lens curvatures, vitreous length and central optical power

\begin{tabular}{|c|c|c|c|c|c|c|c|c|c|c|c|c|c|}
\hline \multirow[t]{2}{*}{ Subject } & \multirow{2}{*}{$\begin{array}{l}\text { Age } \\
\text { (years) }\end{array}$} & \multicolumn{6}{|c|}{ Unaccommodated } & \multicolumn{6}{|c|}{ Change with accommodation } \\
\hline & & $\begin{array}{l}\text { ACD } \\
(\mathrm{mm})\end{array}$ & $\begin{array}{l}\text { CLT } \\
(\mathrm{mm})\end{array}$ & $\begin{array}{l}\text { AR } \\
(\mathrm{mm})\end{array}$ & $\begin{array}{l}\text { PR } \\
(\mathrm{mm})\end{array}$ & $\begin{array}{l}\text { VL } \\
(\mathrm{mm})\end{array}$ & $\begin{array}{l}\text { COP } \\
\text { (diopters) }\end{array}$ & $\begin{array}{l}\text { ACD } \\
(\mu \mathrm{m})\end{array}$ & $\begin{array}{l}\text { CLT } \\
(\mu \mathrm{m})\end{array}$ & $\begin{array}{l}\text { AR } \\
(\mathrm{mm})\end{array}$ & $\begin{array}{l}\text { PR } \\
(\mathrm{mm})\end{array}$ & $\begin{array}{l}\text { VL } \\
(\mathrm{mm})\end{array}$ & $\begin{array}{l}\text { COP } \\
\text { (diopters) }\end{array}$ \\
\hline I & 24 & 3.27 & 3.96 & 10.2 & -6.6 & 15.37 & 20.67 & -40 & 100 & -3.4 & 2.1 & -0.05 & 9.69 \\
\hline 2 & 21 & 3.89 & 3.31 & 10.4 & -6.3 & 16.72 & 21.16 & -110 & 130 & -3.5 & 1.2 & -0.01 & 7.01 \\
\hline 3 & 20 & 3.83 & 3.5 & 10.5 & -6.1 & 16.75 & 21.50 & -50 & 120 & -3.4 & 1.1 & -0.06 & 6.64 \\
\hline Average & 21.7 & 3.66 & 3.59 & 10.4 & -6.4 & 16.28 & 21.11 & -67 & 117 & -3.4 & 1.5 & -0.04 & 7.78 \\
\hline SD & 2.1 & 0.34 & 0.33 & 0.13 & 0.25 & 0.79 & 0.42 & 37.9 & 15.3 & 0.03 & 0.56 & 0.03 & 1.66 \\
\hline
\end{tabular}

Abbreviations: ACD, anterior chamber depth; AR, anterior lens radius; CLT, central lens thickness; COP, central optical power; PR, posterior lens radius; $\mathrm{VL}$, vitreous length. 


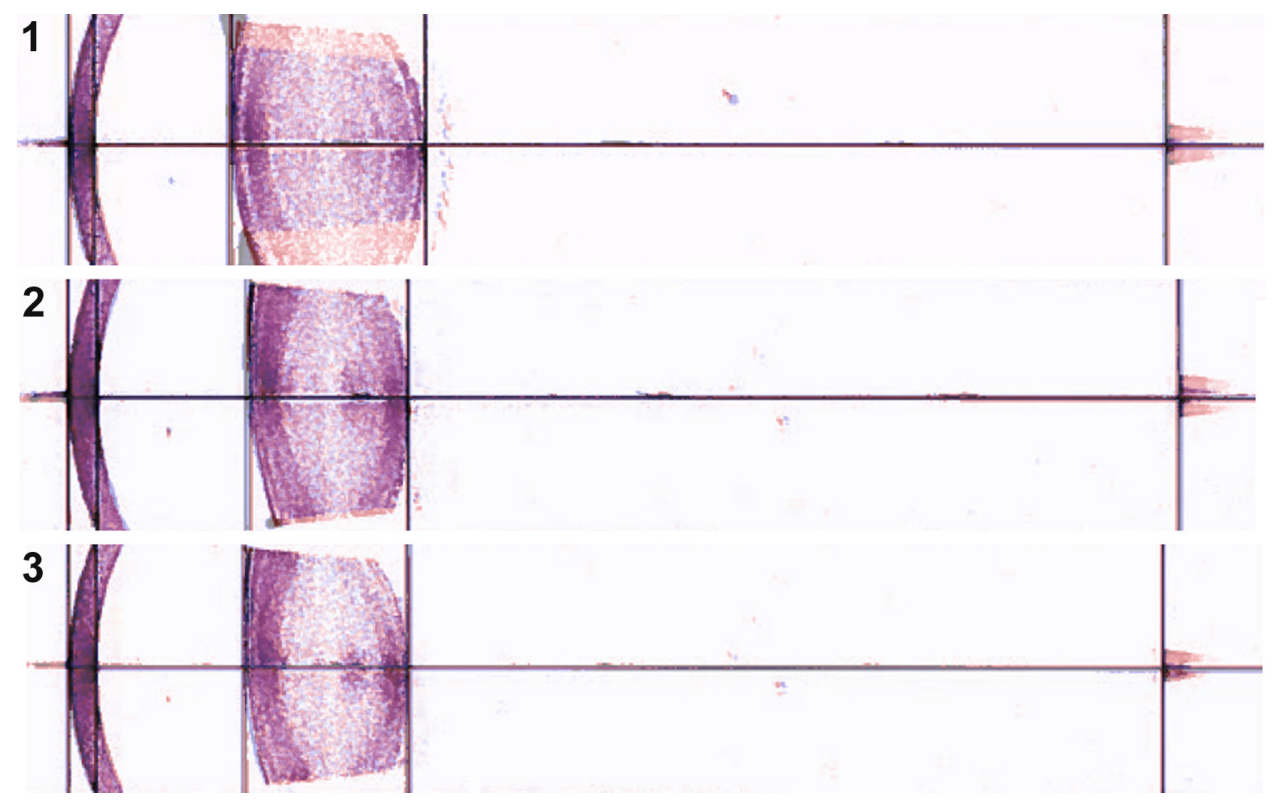

Figure 6 Images of the complete sagittal section of the eyes of subjects I, 2 and 3 with registration of the corneas and foveas. Notes: Accommodated image (blue) on top of the unaccommodated image (red) of subjects I, 2 and 3 . As shown by the apparent lack of movement of the lens nucleus, the whole lens did not move. There was no anterior, posterior or downward movement of the whole lens.

greater resolution than the swept-source optical coherence tomographer for imaging the whole eye.

As imaging modalities improve and incorporate image registration, it will be possible to more reliably assess changes in lens thickness and lens surface curvatures during accommodation. As is evidenced by this work, it is imperative that stringent image registration techniques be used that include unchanging stable references for precise image correspondence to evaluate changes in the eye that occur with accommodation.

\section{What was known}

- Previous studies that did not incorporate image registration with non-changing positional references for image comparison found: 1) A large accommodative change in central lens thickness of $\sim 45 \mu \mathrm{m} /$ diopter. 2) The whole lens appeared to move anteriorly.

\section{What this article adds}

- High resolution techniques that incorporate image registration with stable unchanging references are required to properly assess changes associated with accommodation.

- With precise image registration, central lens thickness minimally increases $16 \mu \mathrm{m} /$ diopter.

- The lens is stable during accommodation. The whole lens does not move anteriorly, posteriorly or downward during accommodation.

\section{Acknowledgments}

The authors wish to thank Tobias Winckler (Jena, Germany) and David Allen (Dublin, CA) from Carl Zeiss Meditec, Inc. for their assistance. These data were presented in part at the annual meeting of the American Society of Cataract and Refractive Surgery, "Best Paper of the Session." May 5-9, 2017.

\section{Disclosure}

The authors report no conflicts of interest in this work.

\section{References}

1. von Helmholtz H. Uber die akkommodation des auges. Archiv für Ophthalmol. 1855;1:1-74.

2. Chien $\mathrm{CH}$, Huang T, Schachar R. Analysis of human crystalline lens accommodation. $J$ Biomech. 2006;39(4):672-680.

3. Schachar RA, Bax AJ. Mechanism of human accommodation as analyzed by nonlinear finite element analysis. Compr Ther. 2001;27(2):122-132.

4. Schachar RA. The Mechanism of Accommodation and Presbyopia. Amsterdam: Kugler Publications; 2012.

5. Enright JT. Ocular translation and cyclotorsion due to changes in fixation distance. Vision Res. 1980;20(7):595-601.

6. Buehren T, Collins MJ, Loughridge J, Carney LG, Iskander DR. Corneal topography and accommodation. Cornea. 2003;22(4):311-316.

7. Steffen H, Walker MF, Zee DS. Rotation of listing's plane with convergence: independence of eye position. Invest Ophthalmol Vis Sci. 2000; 41(3):715-721.

8. Duke-Elder SS, Wybar K. Ocular motility and strabismus. In: Duke-Elder SS, editor. System of Ophthalmology. Vol 6. London: Henry Kimpton; 1973:96-100.

9. Grulkowski I, Liu JJ, Zhang JY, et al. Reproducibility of a long-range swept-source optical coherence tomography ocularbiometry system and comparison with clinical biometers. Ophthalmology. 2013;120(11): $2184-2190$. 
10. Choma MA, Sarunic MV, Yang C, Izatt JA. Sensitivity advantage of swept source and Fourier domain optical coherence tomography. Opt Express. 2003;11(18):2183-2189.

11. IOLMaster 700. User Manual, Jena: Carl Zeiss Meditec; 2015.

12. Kunert KS, Peter M, Blum M, et al. Repeatability and agreement in optical biometry of a new swept-source optical coherence tomography-based biometer versus partial coherence interferometry and optical low-coherence reflectometry. J Cataract Refract Surg 2016;42(1):76-83.

13. Sisó-Fuertes I, Domínguez-Vicent A, del Águila-Carrasco A, FerrerBlasco T, Montés-Micó R. Corneal changes with accommodation using dual Scheimpflug photography. J Cataract Refract Surg. 2015;41(5): 981-989.

14. Drexler W, Findl O, Schmetterer I, Hitzenberger CK, Fercher AF. Eye elongation during accommodation in humans: differences between emmetropes and myopes. Invest Ophthalmol Vis Sci. 1998;39(11): 2140-2147.

15. Cha DI, Lee MW, Song KD, et al. A prospective comparison between auto-registration and manual registration of real-time ultrasound with MR images for percutaneous ablation or biopsy of hepatic lesions Abdom Radiol (NY). 2017;42(6):1799-1808.

16. Che C, Mathai TS, Galeotti J. Ultrasound registration: a review. Methods. 2017;115:128-143.

17. Cleary K, Peters TM. Image-guided interventions: technology review and clinical applications. Annu Rev Biomed Eng. 2010;12: 119-142.

18. Gu Y, McNamara JA Jr. Cephalometric superimpositions. A comparison of anatomical and metallic implant methods. Angle Orthod. 2008 78(6):967-976.

19. Hill DL, Batchelor PG, Holden M, Hawkes DJ. Medical image registration. Phys Med Biol. 2001;46(3):R1-R45.

20. Kim JS, Ishikawa H, Sung KR, et al. Retinal nerve fibre layer thickness measurement reproducibility improved with spectral domain optical coherence tomography. Br J Ophthalmol. 2009;93(8) 1057-1063.

21. Chin EK, Sedeek RW, Li Y, et al. Reproducibility of macular thickness measurement among five OCT instruments: effects of image resolution, image registration, and eye tracking. Ophthalmic Surg Lasers Imaging 2012;43(2):97-108.

22. Mendez N, Kommana SS, Szirth B, Khouri AS. Structural changes by spectral domain optical coherence tomography in patients with type 1 diabetes mellitus. J Diabetes Sci Technol. 2015;10(2): 271-276.

23. Sohrab MA, Smith RT, Salehi-Had H, Sadda SR, Fawzi AA. Image registration and multimodal imaging of reticular pseudodrusen. Invest Ophthalmol Vis Sci. 2011;52(8):5743-5748.

24. Ramsey DJ, Sunness JS, Malviya P, Applegate C, Hager GD, Handa JT. Automated image alignment and segmentation to follow progression of geographic atrophy in age-related macular degeneration. Retina 2014;34(7):1296-1307.

25. Martinez-Enriquez E, Pérez-Merino P, Velasco-Ocana M, Marcos S. OCT-based full crystalline lens shape change during accommodation in vivo. Biomed Opt Express. 2017;8(2):918-933.

26. Doughty MJ, Lyle W, Trevino R, Flanagan JA. A study of mydriasis produced by topical phenylephrine $2.5 \%$ in young adults. Can J Optom. 1988;50:40-60.

27. Barbee RF, Smith WO. A comparative study of mydriatic and cycloplegic agents. Am J Ophthalmol. 1957;44(5):617-622.

28. Salminen L, Aaltonen H, Jäntii V. Mydriatic effect of low dose phenylephrine. Ophthalmic Res. 1980;12(4):235-239.

29. Hoang TA, Macdonnell JE, Mangan, et al. Time course of pupil center location after ocular drug application. Optom Vis Sci. 2016;93(6): 594-599.

30. Domínguez-Vicent A, Monsálvez-Romín D, Pérez-Vives C, FerrerBlasco T, Montés-Micó R. Measurement of angle Kappa with Orbscan II and Galilei G4: effect of accommodation. Graefes Arch Clin Exp Ophthalmol. 2014;252(2):249-255.
31. Kirschkamp T, Dunne M, Barry JC. Phakometric measurement of ocular surface radii of curvature, axial separations and alignment in relaxed and accommodated human eyes. Ophthalmic Physiol Opt. 2004; 24(2):65-73

32. Loewenfeld IE. The Pupil: Anatomy, Physiology and Clinical Applications. Vol. 1. Boston: Butterwoth-Heinemann; 1999.

33. Haegerstrom-Portnoy G, Brabyn J, Schneck ME, Jampolsky A. The skill card. An acuity test of reduced luminance and contrast. SmithKettlewell Institute Low Luminance. Invest Ophthalmol Vis Sci. 1997; 38(1):207-218.

34. Esteve-Taboada JJ, Del Águila-Carrasco AJ, Bernal-Molina P, Ferrer-Blasco T, López-Gil N, Montés-Micó R. Effect of phenylephrine on the accommodative system. J Ophthalmol. 2016; 2016:7968918.

35. León A, Estrada JM, Rosenfield M. Age and the amplitude of accommodation measured using dynamic retinoscopy. Ophthalmic Physiol Opt. 2016;36(1):5-12.

36. Anderson HA, Stuebing KK. Subjective versus objective accommodative amplitude: preschool to presbyopia. Optom Vis Sci. 2014;91(11): 1290-1301.

37. Chang YC, Liu K, de Freitas C, et al. Assessment of eye length changes in accommodation using dynamic extended-depth OCT. Biomed Opt Express. 2017;8(5):2709-2719.

38. Zhu D, Shao Y, Leng L, et al. Automatic biometry of the anterior segment during accommodation imaged by optical coherence tomography. Eye Contact Lens. 2014;40(4):232-238.

39. Bland JM, Altman DG. Statistical methods for assessing agreement between two methods of clinical measurement. Lancet. 1986;1(8476): 307-310.

40. Benzoni JA, Collier JD, McHugh K, Rosenfield M, Portello JK. Does the cross cylinder test measure the accommodative response accurately? Optometry. 2009:80(11):630-634.

41. Horwood AM, Riddell PM. The use of cues to convergence and accommodation in naïve, uninstructed participants. Vision Res. 2008; 48(15):1613-1624.

42. Neri A, Ruggeri M, Protti A, Leaci R, Gandolfi SA, Macaluso C. Dynamic imaging of accommodation by swept-source anterior segment optical coherence tomography. J Cataract Refract Surg. 2015;41(3): 501-510.

43. Jones CE, Atchison DA, Pope JM. Changes in lens dimensions and refractive index with age and accommodation. Optom Vis Sci. 2007; 84(10):990-995.

44. Richdale K, Bullimore MA, Zadnik K. Lens thickness with age and accommodation by optical coherence tomography. Ophthalmic Physiol Opt. 2008;28(5):441-447.

45. Ramasubramanian V, Glasser A. Prediction of accommodative optical response in prepresbyopic patients using ultrasound biomicroscopy. $J$ Cataract Refract Surg. 2015;41(5):964-980.

46. Ni Y, Liu XL, Wu MX, et al. Objective evaluation of the changes in the crystalline lens during accommodation in young and presbyopic populations using Pentacam HR system. Int J Ophthalmol. 2011;4(6): 611-615.

47. Tsorbatzoglou A, Németh G, Széll N, Biró Z, Berta A. Anterior segment changes with age and during accommodation measured with partial coherence interferometry. J Cataract Refract Surg. 2007;33(9): 1597-1601.

48. Dubbelman M, van der Heijde GL, Weeber HA. Change in shape of the aging human crystalline lens with accommodation. Vision Res. 2005;45(1):117-132.

49. Smith G, Atchison DA. The Eye and Visual Optical Instruments. Cambridge: Cambridge University Press; 1997.

50. Schachar RA, Kamangar F. Computer image analysis of ultrasound biomicroscopy of primate accommodation. Eye (Lond). 2006;20(2): 226-233.

51. Schachar RA, Tello C, Cudmore DP, Liebmann JM, Black TD, Ritch R. In vivo increase of the human lens equatorial diameter during accommodation. Am J Physiol. 1996;271(3 Pt 2):R670-R676. 
52. Chin EK, Sedeek RW, Li Y, et al. Reproducibility of macular thickness measurement among five OCT instruments: effects of image resolution, image registration, and eye tracking. Ophthalmic Surg Lasers Imaging. 2012;43(2):97-108.

53. Liu S, Datta A, Ho D, et al. Effect of image registration on longitudinal analysis of retinal nerve fiber layer thickness of non-human primates using optical coherence tomography (OCT). Eye Vis (London). $2015 ; 2: 3$.
54. Lang A, Carass A, Al-Louzi O, et al. Combined registration and motion correction of longitudinal retinal OCT data. Proc SPIE Int Soc Opt Eng. 2016;9784:1-15.
Clinical Ophthalmology

\section{Publish your work in this journal}

Clinical Ophthalmology is an international, peer-reviewed journal covering all subspecialties within ophthalmology. Key topics include: Optometry; Visual science; Pharmacology and drug therapy in eye diseases; Basic Sciences; Primary and Secondary eye care; Patient Safety and Quality of Care Improvements. This journal is indexed on

\section{Dovepress}

PubMed Central and CAS, and is the official journal of The Society of Clinical Ophthalmology (SCO). The manuscript management system is completely online and includes a very quick and fair peer-review system, which is all easy to use. Visit http://www.dovepress.com/ testimonials.php to read real quotes from published authors. 